\title{
INCLUSÃO DA CRIANÇA COM ESPECTRO AUTISTA EM SALA DE AULA: DESAFIOS E PERSPECTIVAS FAMILIARES
}

\author{
INCLUSION OF CHILDREN WITH AUTISM SPECTRUM IN THE CLASSROOM: \\ CHALLENGES AND FAMILY PERSPECTIVES
}

\author{
iD Parley Lopes Bernini Silva \\ Mestrado em Extensão Rural \\ Universidade Federal de Viçosa -UFV. \\ Viçosa, Minas Gerais - Brasil. \\ parley.silva@ufv.br
}

Ana Paula Gouvêa

Especialista latu sensu em Educação Inclusiva Centro Universitário Presidente Antônio Carlos - UNIPAC. Barbacena, Minas Gerais - Brasil. anagouvea@yahoo.com.br

\author{
Silvana de Araujo Castro de Oliveira \\ Especialista latu sensu em Educação Inclusiva \\ Centro Universitário Presidente Antônio Carlos - UNIPAC. \\ Barbacena, Minas Gerais - Brasil. \\ acoliveirasilvana@gmail.com
}

\begin{abstract}
Resumo: $\mathrm{O}$ artigo analisa os significados atribuídos pelos pais de crianças diagnosticadas com Transtorno do Espectro Autista ao ingresso de seus filhos no ensino regular em Barbacena-MG, sobretudo nos aspectos psicossociais. Metodologicamente demarcado como qualitativo, a aplicação de 12 questionários semiestruturados, aliada ao resgate na literatura pertinente, ofertou o aporte deste trabalho. A análise evidenciou que a percepção dos genitores emerge de que o espaço escolar não se encontra apto para receber seus filhos, sem profissionais capazes de atender suas demandas e peculiaridades, limitando a equidade no ensino. Conclui-se que suas representações são polissêmicas acerca dessa inserção e centralizadas pelo que se tem nos meios de informação, especialmente pela comunicação informal, rotineira, do cotidiano. Após coleta dos dados, revelou-se a necessidade de uma análise mais densa e particularizada deste fenômeno, aliada às falas pelos respondentes.
\end{abstract}

Palavras-chave: autismo; família; inclusão escolar.

Abstract: The article analyzes the meanings attributed by parents of children diagnosed with Autistic Spectrum Disorder to their children's entry into regular education in Barbacena-MG, especially in terms of psychosocial aspects. Methodologically demarcated as qualitative, the application of 12 semi-structured questionnaires, together with the search in the relevant literature, provided the contribution of this work. The analysis showed that the perception of parents emerges that the school space is not able to receive their children, without professionals capable of meeting their demands and peculiarities, limiting equity in education. It is concluded that their representations are polysemy about this insertion and centered on what is found in the media, especially through informal, routine, everyday communication. After collecting the data, it was revealed the need for a denser and more detailed analysis of this phenomenon, together with the speeches by the respondents.

Keywords: autism; family; school inclusion.

Para citar - ABNT NBR 6023:2018

BERNINI SILVA, Parley Lopes; GOUVÊA, Ana Paula; OLIVEIRA, Silvana de Araujo Castro. Inclusão da criança com espectro autista em sala de aula: desafios e perspectivas familiares. Cadernos de Pós-graduação, São Paulo, v. 20, n. 2, p. 150-164, jul./dez. 2021. Disponível em: https://doi.org/10.5585/cpg.v20n2.20650. 
Introdução

Os estudos que referenciam o Transtorno do Espectro Autista (TEA) tornaram-se foco de pesquisas mais atuais (ABRA, 2019; NUNES; SCHMIDT, 2019; MANDAL, 2019), haja vista que se caracteriza enquanto um distúrbio de desenvolvimento que acompanha o indivíduo durante sua vida, assim como associa-se aspectos ligados à comunicação e ao comportamento e à interação social; “observados nos anos iniciais da infância, esta condição é revelada através de diagnóstico médico" (ABRA, 2019, n. p.).

Assim, percebe-se a complexidade própria desta condição e suas características, demandando uma atenção especial em múltiplos espaços, tal qual a família, a escola e demais pessoas que interagem com estes indivíduos (NUNES; SCHIMIDT, 2019). Os desafios da criança autista em sua inserção nos diversos espaços que lhe cabem são de uma variedade ímpar, sendo necessário que se tenha uma abordagem apropriada e eficiente, de maneira que consiga se desenvolver adequadamente ao longo de sua vida escolar e social.

No contexto educacional, por sua vez, a inclusão de cidadãos com deficiência é palco de constantes debates e discussões, levando à reflexão sobre novas possibilidades dentro do processo de ensino e aprendizagem. Assim, o tema da educação inclusiva, com recorte em estudantes autistas, passou a despertar questionamentos principalmente pela transformação de todo o sistema educacional brasileiro, que prevaleceu por muitas décadas excludente, para um inclusivo e orientado à multidisciplinaridade de saberes (ABRA, 2019), sendo assim transformado e transformador do grupo social em que se insere (SEVERINO, 2007).

A partir desse pressuposto, a presente observação ancorou em realizar um estudo no que tange às aspirações dos pais de crianças diagnosticadas com Transtorno do Espectro Autista, popularmente referenciado como autismo e suas representações sobre o ingresso de seus filhos no ensino básico, tal qual o que julgam como desafios deste fenômeno, sobretudo nos aspectos psicossociais dos seus filhos ao iniciarem tal atividade.

O objetivo central da pesquisa é perceber quais são os anseios das famílias de crianças com TEA para sua concretização do processo inclusivo frente às possibilidades de inserção em escolas regulares de ensino. O estudo se releva na busca do saber próprio da formação especializada em educação inclusiva, capaz de compreender as especificidades desse trabalho pedagógico, buscando reduzir as arestas presentes no processo de ensino aprendizagem e, consequentemente, gerar visibilidade a esse público, o qual carece de atendimento específico.

Este tipo de pesquisa busca contribuir no desenvolvimento científico contemporâneo e promover novos estudos relacionados ao tema elencado, bem como revisões acerca de Educação 
e Inclusão, considerando que na literatura brasileira se faz presente um espaço em branco que referencie estratégias que correlacionem a escola com o TEA ${ }^{1}$, bem como a formação docente precária capaz de atender esses cidadãos ${ }^{2}$.

Esta atividade se torna válida, uma vez que a academia é espaço de criação e transmissão de saberes, do conhecimento e da inovação, sendo a propulsora do desenvolvimento social, econômico, político, científico e cultural de qualquer sociedade à qual pertença (CABRAL; SILVA; SAITO, 2011), sendo necessária a discussão para além das universidades, visto que "conjectura-se que o conhecimento acadêmico que alicerça estratégias interventivas cientificamente validadas não esteja sendo repassado da academia para as práticas docentes" (NUNES; SCHIMIDT, 2019, p. 87), de maneira que se restringem tão-só ao cenário universitário. Percebe-se, então, que são esses ambientes de aprendizagem capazes de proporcionar a formação e a emancipação do ser humano, educando cidadãos com pensamento crítico de forma a buscar melhorias para sua comunidade, local que vivem e convivem.

De excepcional, autista e transtorno do espectro autista: sob um debate teórico constante

Empregado inicialmente em 1908, por Eugen Bleuler, o Transtorno do Espectro Autista tinha ênfase àqueles ditos esquizofrênicos, aos que se ausentavam do próprio mundo. Assim "a palavra grega 'autós' significou que o auto e a palavra 'autismo' estiveram usados por Bleuler para significar a autoadmiração mórbido e a retirada do auto” (MANDAL, 2019, n. p).

Hans Asperger e Leo Kanner foram os pioneiros a se dedicarem às análises que aludem ao TEA, ambos em óticas distintas, em 1940. Asperger descrevia as crianças como suficientemente capazes e Kanner como severamente afetadas. As visões destes pesquisadores foram o alicerce para o exercício da Medicina nas próximas décadas (MANDAL, 2019). Igualmente, as contribuições de Bruno Bettelheim (estudos de autistas sem as mães acompanhando); Bernard Rimland (psicologia com pais de crianças autistas); LornaWing e Christopher Gillberg (análises entre comunicação e imaginação) e Ole Ivar Lovaas (análise behavarial no tratamento de crianças com TEA) favoreceram o debate e construção teórica do que se tem atualmente sobre esse transtorno (MANDAL, 2019). Mais ainda, corroborando com as premissas ditas acima, Wuo (2019, p.2013 apud FADDA; CURY, 2016), versa que estes:

\footnotetext{
${ }^{1}$ Mais estudos ver AZEVEDO, 2017; NASCIMENTO et al, 2016.

${ }^{2}$ Mais estudos ver NUNES et al, 2013; SCHMIDT et al, 2016.
} 
Realizaram uma revisão de literatura acerca das explicações etiológicas do autismo e apresentam quatro paradigmas distintos: o paradigma biológico-genético, que entende o autismo como doença neurológica congênita; o paradigma relacional, que atribui às causas do autismo as falhas na relação mãe-bebê; o paradigma ambiental, que define o autismo como uma lesão neurológica provocada por agentes ambientais no período prénatal, perinatal ou pós-natal; e o paradigma da neurodiversidade, que refuta os três paradigmas anteriores, pois vê o autismo como uma diferença que caracteriza a singularidade do sujeito e não uma doença que precise ser medicada, controlada, diagnosticada.

É notável que nos últimos anos a literatura vem historiando um aumento considerável de estudantes diagnosticados com TEA nas classes regulares de ensino, exigindo uma formação qualificada dos docentes e da escola em si (NUNES; SCHIMIDT, 2019), especialmente após a Política Nacional de Educação Especial na Perspectiva de Educação Inclusiva, em 2008 (WUO, 2019). Há, assim, a necessidade de desenvolver instrumentos capazes de atender às peculiaridades destes atores no âmbito escolar, das quais Nunes e Schimidt (2019, p. 90-91) glosam que:

\begin{abstract}
Nacionalmente, vale destacar a Nota Técnica n. 24/2013/MEC/Secadi/DPEE, que, embora de forma tímida, enumera um conjunto de competências docentes para atuar com alunos com autismo (BRASIL, 2013). É interessante observar que ambos os documentos - o CEC e a Nota Técnica n. 24 - remetem, de forma direta ou indireta, ao uso de PBE. O CEC (2009) indica explicitamente que uma das competências a serem desenvolvidas pelo professor é demonstrar o compromisso de implementar práticas baseadas em evidências. [...] Em revisão integrativa de 22 estudos sobre práticas pedagógicas desenvolvidas com esse alunado na escola regular, Azevedo (2017) observou que menos de $20 \%$ dos agentes educacionais possuíam formação na área de educação especial, não sendo relatada qualquer capacitação específica em autismo. No estudo de Schmidt e colaboradores (2016), mais da metade dos 29 professores de alunos com autismo não possuía qualquer formação complementar, além da graduação em Pedagogia.
\end{abstract}

Pode-se, assim, problematizar este fenômeno como resultante de políticas nacionais, as quais referenciam precarização da formação docente para a educação inclusiva. Esse tipo de ação, “como alertam Fonseca-Janes, Silva Júnior e Oliveira (2013), destituíram o pedagogo - antes habilitado em cursos de Pedagogia em uma ou mais deficiência - da atuação na área da educação especial" (NUNES; SCHIMIDT, 2013, p. 91).

Vê-se que com a fragilização da habilitação dos Cursos Superiores de Pedagogia, dispostas pela Resolução CNE/2006 (BRASIL, 2006), os professores de educação especial tiveram sua substituição, gradual, por outros que sequer dispunham do mesmo nível de formação. É nessa perspectiva que Nunes e Schimidt (2019, p. 91-92), comentam que: 


\begin{abstract}
A formação dos professores especializados em educação especial, conforme definido pela Resolução CNE/2001 (BRASIL, 2001), passou a ocorrer primordialmente em nível de pós-graduação, em cursos lato sensu (MICHELS, 2011; FONSECA-JANES; SILVA JR.; OLIVEIRA, 2013). Esse tipo de formação, respaldada pela Política Nacional de Educação Especial na Perspectiva da Educação Inclusiva (BRASIL, 2008), habilita esse professor a atender aos alunos público-alvo da educação especial, por meio do atendimento educacional especializado (AEE), no contexto das salas de recursos multifuncionais.
\end{abstract}

A proposta de uma formação a nível latu e que atenda a este público é, sem dúvidas, um avanço considerável a estes sujeitos com uma atenção para além da graduação. Ainda assim, não se tornou suficiente para a realidade atual que esses cidadãos enfrentam em âmbito escolar, justamente por ir para além do recurso humano. WUO (2019, p. 210), assim, oportuniza também uma análise mais coesa desse tema ao elucidar que:

As atuais políticas de educação especial buscam garantir o acesso, a permanência, a participação e a aprendizagem de pessoas com deficiência, transtornos globais do desenvolvimento e altas habilidades/superdotação na escola comum (BRASIL,2008, 2015). Conforme a Política Nacional de Educação Especial na Perspectiva da Educação Inclusiva (PNEEPEI) (BRASIL, 2008), os estudantes com transtorno do espectro autista (TEA), foco desta pesquisa, fazem parte do público-alvo da educação especial (PAEE) e são inseridos na categoria transtornos globais do desenvolvimento.

Assim, o transtorno foi inserido nas políticas destinadas à educação no ano de 1944, respaldado pela Política Nacional de Educação Especial, categorizado como condutas atípicas. Como WUO (2019, p. 211 apud BRASIL, 1994, p. 12), elucida, entende-se o termo como:

Manifestações de comportamento típicas de portadores de síndromes e quadros psicológicos, neurológicos, ou psiquiátricos que ocasionam atrasos no desenvolvimento e prejuízos no relacionamento social, em grau que requeira atendimento educacional especializado.

Diante desse situação, faz-se presente a busca pela equidade desses cidadãos em cenário nacional, disposta pela Lei no 12.764 , de 27 de dezembro de 2012, estabelecendo a Política Nacional dos Direitos da Pessoa com Transtorno do Espectro Autista que, dentre seus tópicos, destaca (BRASIL, 2012):

\footnotetext{
Art. 1 Esta Lei institui a Política Nacional de Proteção dos Direitos da Pessoa com Transtorno do Espectro Autista e estabelece diretrizes para sua consecução. [...] \ $2^{\circ}$ A pessoa com transtorno do espectro autista é considerada pessoa com deficiência, para todos os efeitos legais. Art. 3 São direitos da pessoa com transtorno do espectro autista:[...] IV- o acesso: a) à educação e ao ensino profissionalizante; Parágrafo único. Em casos de comprovada necessidade, a pessoa com transtorno do espectro autista incluída nas classes comuns de ensino regular, nos termos do inciso IV do art. $2^{\circ}$, terá direito a acompanhante especializado.
} 
Como orientações para o processo de educação dos indivíduos diagnosticados com TEA, há sobretudo garantia de sua escolarização (seja em escolas comuns e de atendimento especializado educacional -AEE-). Mais ainda, deve-se ter como pilar essa colaboração e observância "de políticas públicas voltadas para as pessoas com TEA [...]; a responsabilidade do poder público quanto à informação pública sobre o TEA; o incentivo à formação e à capacitação de profissionais especializados; e o estímulo à pesquisa científica" (WUO, 2019, p. 22 apud BRASIL, 2012). Em síntese, compete à articulação do ensino regular e outros agentes, como os pais, num plano de atendimento mútuo implementado no contexto regular de ensino, oportunizar a participação conjunta entre estes atores, bem como a construção de políticas que ofertem voz e visibilidade aos protagonistas desta pesquisa (BRASIL, 2012).

Observa-se, em conclusão, a limitação de estudos nacionais que contemplem essa temática e nesse contexto, em especial sobre escolarização e práticas pedagógicas de inclusão (OLIVEIRA; PAULA, 2012; NEVES et al, 2014; NASCIMENTO et al, 2016; PEREIRA, 2016). Neste panorama, esta observação se atém a estudar a amplitude deste tema e as representações sociais, em especial nas perspectivas de ingresso no âmbito escolar, de onde se extrai a análise, partindo de um estudo realizado na cidade de Barbacena-MG.

\section{Representações sociais como formas de conhecimento e interpretação}

O marco da Teoria das Representações advém das representações coletivas da obra de Émile Durkheim no início do século XX e sua reformulação por Serge Moscovici, em 1961 (LOPES, 2013). Moscovici, ao contrário de Durkheim, que entendia as representações como formas de conhecimento estáveis, coletivas, coercitivas e homogêneas, propõe-se a estudar as diferentes configurações de significados e de ação criadas por grupos sociais heterogêneos em uma mesma sociedade. Seus estudos abriram perspectivas investigativas em diferentes disciplinas (ARRUDA, 2002), posto que como psicólogo social, Serge Moscovici priorizou as especificidades dos fenômenos representacionais da sociedade moderna (JODELET, 2001).

As representações sociais (e seu estudo) estabelecem uma interface entre as dimensões sociais, culturais e psicológicas, daí exibirem um status transversal com diversas áreas de pesquisa. É, de tal modo, uma teoria de vinculação (ligação e coesão), onde "a vigilância exercida pelo grupo sobre o indivíduo diminui à medida que os vínculos entre eles se tornam mais densos e recíprocos" (MOSCOVICI, 2001, p. 56). São construídas devido à necessidade de conhecer, compreender, ajustar, dominar, informar ou identificar o que o sujeito tem à sua volta. Assim, a teoria das Representações Sociais busca tratar os fenômenos, observáveis diretamente ou reconstruídos, por 
intervenção da ciência, legitimada como explicação dos processos cognitivos e das interações sociais. Para Sêga (2000, p. 128-29):

\begin{abstract}
As representações sociais se apresentam como uma maneira de interpretar e pensar a realidade cotidiana, uma forma de conhecimento da atividade mental desenvolvida pelos indivíduos e pelos grupos para fixar suas posições em relação a situações, eventos, objetos e comunicações que lhes concernem. É um conhecimento prático que dá sentido aos eventos que nos são normais, forja as evidências da nossa realidade consensual e ajuda a construção social da nossa realidade.
\end{abstract}

Como proposto por Jodelet (2001, p. 17), as representações sociais "nos guiam no modo de nomear e definir conjuntamente os diferentes aspectos da realidade diária, no modo de interpretar esses aspectos, tomar decisões e eventualmente, posicionar-se frente a eles de forma defensiva." De tal forma, as representações não são algo fiel e fidedigno, "nem a parte subjetiva do objeto, nem a parte objetiva do sujeito" (SÊGA, 2000, p. 129), mas sim a coesão entre o mundo, seus objetos e os sujeitos que lhes conferem significados.

A teoria das representações sociais focaliza as formas e conteúdos do conhecimento, priorizando os aspectos cognitivos, emocionais e comunicativos que intervêm na criação, modificação e circulação das imagens e dos significados, daí seu particular interesse pelos discursos, dentre eles os orais, escritos, imagéticos ou propagados pelas diferentes mídias, por exemplo (JODELET, 2001). Outro aspecto da teoria pondera que a representação social “deve ser estudada articulando elementos afetivos, mentais e sociais ao lado da cognição, da linguagem e da comunicação" (ibid., 2001, p. 26), pois a visão de mundo do sujeito (ou do grupo social) e suas ações são explicitadas através do recurso representacional.

Representar implica "agir sobre o mundo e o outro, o que desemboca em suas funções e eficácia sociais" (JODELET 2001, p. 28). Igualmente, implica em dar sentido ao que é vivido e experimentado (PESAVENTO, 1995), marcando pertenças sociais que possibilitam identidades aos membros de uma comunidade, haja vista que "a natureza consensual de uma representação é geralmente parcial e localizada" (LOPES, 2013, p. 25159). Representações são opiniões (tomadas de posição), conhecimentos (relacionados à aprendizagem) e crenças (vinculados a convicções) que sustentam identificações de um determinado grupo social.

A dinamicidade das representações sociais reside no fato de elas serem interpretações de uma realidade, que se modifica no tempo, bem como pela própria circulação dos indivíduos em diferentes grupos sociais, ou seja, embora se torne "um instrumento referencial que permite a comunicação em uma mesma linguagem (SÊGA, 2000, p. 130), a representação está aberta à possibilidade da polissemia, onde ora se apresentam temas inovadores que provocam conversões 
de experiências, de percepções que conduzem a uma nova visão" (ibid., p. 130), ora se preserva a rigidez das formas de pensar e agir já testadas e sancionadas.

Assim, a partilha social alude a um mecanismo de determinações conexas à estrutura e às relações onde dividir uma ideia (ou linguagem) é afirmar vínculos sociais e identificações sujeitos a reformulações e validações constantes (JODELET, 2001). Em síntese, e como colocado por Serge Moscovici (2001, p. 55), as "representações ressaltam os fatos e interpretam uma realidade" que "é socialmente construída e o saber é uma construção do sujeito, mas não desligada da sua inscrição social" (ARRUDA 2002, p. 151). A partir desses pressupostos, a utilização da teoria das representações sociais neste artigo implica em entender as escolas como fenômeno de hibridação onde se partilham, debatem-se e recusam-se ideias e interpretações (SACCO DOS ANJOS et al, 2005). Estes, elementos indissociáveis de qualquer grupo social que partilha da mesma realidade, como o caso dos protagonistas dessa pesquisa.

\section{Percurso metodológico}

O recorte de pesquisa busca analisar as percepções dos pais ${ }^{3}$ de crianças diagnosticadas com TEA e sua inserção no ensino regular. Apresenta características da pesquisa exploratória que, à luz de Vergara (2004), percebe esse fenômeno como desenvolvido numa área a qual exiba escasso saber acumulado e sistematizado, sendo capaz de proporcionar maior familiaridade com o problema (explicitá-lo), tal qual envolvendo o levantamento bibliográfico pertinente à temática que se estuda. O universo empírico delimitou-se ao município de Barbacena-MG e o público participante se respaldou em 12 respondentes.

Estes, responderam um questionário semiestruturado exibindo informações pessoais; dados educacionais; dados relacionados ao eixo ligado ao ensino que afete o especialista em educação inclusiva. Neles, podiam delimitar opiniões ou considerações ao que se indagava. Após coletados foram tabulados e analisados, compondo uma análise interpretativa do tema proposto, correlacionada aos fatos sociais abordados por outras pesquisas acadêmicas que contemplam essa mesma temática. Vale destacar que a observação também exibe viés metodológico analítico, com a interpretação detalhada dos resultados (GIL, 2008).

\footnotetext{
${ }^{3}$ Há de se destacar que as abordagens e os instrumentos metodológicos utilizados obedeceram aos procedimentos éticos estabelecidos para a pesquisa científica em Ciências Humanas, sobretudo ao sigilo dos pesquisados.
} 
Resultados e discussão

A partir da pergunta ${ }^{4}$ um, onde se questionava "O que você considera como prioridades para um ensino inclusivo dentro da escola?", obteve-se a tabela (TABELA 1) disposta:

Tabela 1 - Pergunta 1

\begin{tabular}{|c|c|c|c|c|c|c|}
\hline & $\begin{array}{c}\text { Participação } \\
\text { conjunta entre } \\
\text { pais e escola } \\
\text { no processo } \\
\text { de } \\
\text { aprendizagem }\end{array}$ & $\begin{array}{l}\text { Promover } \\
\text { ações que } \\
\text { mostrem a } \\
\text { necessidade de } \\
\text { pensar na } \\
\text { inclusão }\end{array}$ & $\begin{array}{c}\text { Oferecer } \\
\text { recursos } \\
\text { pedagógicos } \\
\text { direcionados } \\
\text { as crianças } \\
\text { com TEA }\end{array}$ & $\begin{array}{c}\text { Atuação de } \\
\text { profissionais } \\
\text { em } \\
\text { educação } \\
\text { inclusiva } \\
\end{array}$ & $\begin{array}{c}\text { Capacitação } \\
\text { de } \\
\text { professores, } \\
\text { diretores e } \\
\text { os demais } \\
\text { profissionais } \\
\end{array}$ & $\begin{array}{c}\text { Proporcionar } \\
\text { espaços de debate } \\
\text { que apresentem a } \\
\text { necessidade de se } \\
\text { falar sobre TEA }\end{array}$ \\
\hline E1 & $\operatorname{sim}$ & $\operatorname{sim}$ & sim & $\operatorname{sim}$ & $\operatorname{sim}$ & $\operatorname{sim}$ \\
\hline E2 & $\operatorname{sim}$ & $\operatorname{sim}$ & $\operatorname{sim}$ & $\operatorname{sim}$ & $\operatorname{sim}$ & não \\
\hline E3 & $\operatorname{sim}$ & $\operatorname{sim}$ & sim & $\operatorname{sim}$ & $\operatorname{sim}$ & $\operatorname{sim}$ \\
\hline E4 & sim & $\operatorname{sim}$ & sim & $\operatorname{sim}$ & $\operatorname{sim}$ & $\operatorname{sim}$ \\
\hline E5 & $\operatorname{sim}$ & $\operatorname{sim}$ & $\operatorname{sim}$ & $\operatorname{sim}$ & $\operatorname{sim}$ & $\operatorname{sim}$ \\
\hline E6 & $\operatorname{sim}$ & $\operatorname{sim}$ & $\operatorname{sim}$ & $\operatorname{sim}$ & $\operatorname{sim}$ & $\operatorname{sim}$ \\
\hline E7 & $\operatorname{sim}$ & não & $\operatorname{sim}$ & não & $\operatorname{sim}$ & กão \\
\hline E8 & sim & $\operatorname{sim}$ & $\operatorname{sim}$ & $\operatorname{sim}$ & sim & $\operatorname{sim}$ \\
\hline E9 & $\operatorname{sim}$ & $\operatorname{sim}$ & sim & $\operatorname{sim}$ & $\operatorname{sim}$ & กão \\
\hline E10 & sim & $\operatorname{sim}$ & $\operatorname{sim}$ & $\operatorname{sim}$ & $\operatorname{sim}$ & $\operatorname{sim}$ \\
\hline E11 & $\operatorname{sim}$ & $\operatorname{sim}$ & $\operatorname{sim}$ & $\operatorname{sim}$ & $\operatorname{sim}$ & $\operatorname{sim}$ \\
\hline E12 & sim & $\operatorname{sim}$ & sim & $\operatorname{sim}$ & sim & não \\
\hline
\end{tabular}

Fonte: Dados da pesquisa, 2019.

Questionados, os respondentes podiam assinalar mais de uma alternativa, onde "sim" representa concordância com o que se questiona e "não" que discordam. A partir do exposto, pode-se estabelecer que a presença de respostas negativas, por sua vez, faz alusão à pouca profissionalização especializada para atender a criança com TEA; à insuficiente publicação nas mídias do que é o transtorno e sobretudo de espaços que dialoguem e debatam o que é esta condição e sua necessidade de pulverização nos cenários acadêmicos; sociais; políticos e culturais. Premissas às quais dedicaram-se a contextualizar Schimidt et al (2016); Nunes; Schimidt (2016) e Brasil (2012) 
A pergunta dois, por sua vez, indagava se o respondente "acha que politicas públicas podem contribuir no processo de inserção do (a) seu (sua) filho (a)? Dê exemplos", alguns relatos merecem destaque, a saber:

Sim. Através de divulgação do TEA, suas leis e direitos, cursos de capacitação para professores, etc. $(\boldsymbol{E} 7)$

Pode e deve, mas infelizmente a Lei da Inclusão não sai do papel. Deveria se criar comissões de profissionais nas escolas públicas, com material específico didático, para trabalhar a educação inclusiva juntamente com a família. (E\&)

Através das respostas pode-se perceber a percepção dos respondentes sobre o tema, em especial como se faz necessária a execução da legislação nestes casos. Mais ainda, há espaço para uma análise mais profunda, densa e direcionada à visão dos atores, onde reforçam a ideia de que o indivíduo diagnosticado com TEA detém dos mesmos direitos que todos os demais, desvencilhando-se da teoria exercida por Eugen Bleuler de que são pessoas com mundos isolados e aproximando-se dos estudos que Schmidt et al (2016), dedicaram-se analisar. Como aludido por uma entrevistada:

A pessoa com deficiência é um ser humano que merece atenção e respeito, e que deveria ser aceita pela sociedade sem discriminação, mas na realidade as coisas funcionam diferentes. Existem muitas barreiras que precisam ser ultrapassadas para que estas pessoas sejam inclusas socialmente como cidadãs, com direitos e qualidade de vida. Existem também diversas políticas públicas que foram criadas a fim de garantir direitos às pessoas com necessidades educacionais especiais. (E10)

E reforçado por outra:

Para garantir o direito de todos os alunos, independente da sua condição, de estarem juntos participando e aprendendo, sem ser discriminado, o Ministério da Educação apresenta a Política Nacional de Educação Especial na Perspectiva da Educação Inclusiva, que visa constituir políticas públicas promotoras de uma educação de qualidade para todos. [...]. Atualmente muitas escolas já adotam a inclusão, mas infelizmente existem professores sem qualificação para trabalhar com criança especial. Algumas escolas oferecem o Atendimento Educacional Especializado (AEE) no contra turno, com professores capacitados para ensinar as crianças com necessidades educacionais especiais (NEE). (E11)

As repostas apresentam, por sua vez, a concepção de que os pais compreendem a situação de seus filhos e os direitos que lhes convêm (BRASIL, 2012). Ainda assim, reconhecem que há uma limitação docente que consiga suprir os desafios de seus filhos se comparados com os demais estudantes. Perceber que "a Lei garante educação para todos, mas isso não acontece na prática. Muitos 
acreditam que crianças especiais devam frequentar escolas especiais. Mas e a inclusão? É dever do Estado oferecer ensino em escolas regulares para essas crianças" (E11) demonstra, num plano político e social, a fragilidade das ações que de fato atendam àqueles diagnosticados com TEA (NUNES, 2013; PEREIRA, 2016; NUNES; SCHIMIDT, 2019; WUO, 2019). Essa situação é reforçada ao ler que dentre as políticas de inclusão é destacado "[...] a Constituição de 1988, o PNE- Plano Nacional de Educação, a Declaração de Salamanca, a Convenção sobre os Direitos das Pessoas com Deficiência, dentre outras, que ficam apenas no papel." (E10).

Ao que alude a questão três, onde questionava se "acredita que a escola onde seu (sua) filho (a) irá estudar está pronta para recebê-lo (la)? Indique a resposta que mais se identifica", 66\% assinalaram que não apresentam certeza; 16\% apontaram que possuem média certeza disso a par de $16 \%$ que disseram ter total certeza de que a escola está preparada. As respostas majoritárias, por sua vez, oportunizam exercer uma comparação com o disposto por Nunes e Schmidt (2019, p. 90-91), quando comentam que "no Brasil, as lacunas na formação docente para atuar com educandos com autismo parecem ainda mais acentuadas", aspecto esse que justifica o receio dos pais ao inserirem seus filhos no ensino regular.

Já a questão quatro pedia que os pesquisados delimitassem o que acreditavam "ser um limitador no ingresso do (a) seu (sua) filho (a) no ensino básico regular?"; por resultados obteve-se (TABELA 2):

\section{Tabela 2 - pergunta 4}

$\begin{array}{cccc}\begin{array}{c}\text { Pouca divulgação } \\ \text { de escolas que }\end{array} & \begin{array}{c}\text { Políticas Públicas de } \\ \text { acessibilidade } \\ \text { recebem TEA }\end{array} & \begin{array}{c}\text { Dificuldade de } \\ \text { diálogo entre pais e }\end{array} & \begin{array}{c}\text { Número de informações } \\ \text { nos canais de } \\ \text { comunicação sobre o que }\end{array} \\ \text { erofessores } & \begin{array}{c}\text { é TEA } \\ \hline\end{array}\end{array}$

\begin{tabular}{lllll}
\hline E1 & $\mathrm{X}$ & $\mathrm{X}$ & & $\mathrm{X}$ \\
E2 & & $\mathrm{X}$ & $\mathrm{X}$ & $\mathrm{X}$ \\
E3 & & & $\mathrm{X}$ & \\
E4 & $\mathrm{X}$ & $\mathrm{X}$ & \\
E5 & $\mathrm{X}$ & $\mathrm{X}$ & & $\mathrm{X}$ \\
E6 & $\mathrm{X}$ & $\mathrm{X}$ & & $\mathrm{X}$ \\
E7 & $\mathrm{X}$ & $\mathrm{X}$ & $\mathrm{X}$ \\
E8 & $\mathrm{X}$ & $\mathrm{X}$ & $\mathrm{X}$ & \\
E9 & & $\mathrm{X}$ & & \\
E10 & & $\mathrm{X}$ & & \\
E11 & & & & \\
E12 & & & & \\
\hline
\end{tabular}

Fonte: Dados da pesquisa, 2019. 
É através da tabela que se revelam os tópicos analisados como importantes pelos respondentes, onde apontam, dentre outros, a necessidade de políticas públicas direcionadas aos diagnosticados com TEA; maior divulgação do que é o transtorno nos meios de comunicação e a amplitude de escolas que acolham seus filhos.

Ainda que "[...] Art.7 O gestor escolar, ou autoridade competente, que recusar a matrícula de aluno com transtorno do espectro autista, ou qualquer outro tipo de deficiência, será punido com multa de 3 (três) a 20 (vinte) salários-mínimos" (BRASIL, 2012, p. 2), notou-se que a preocupação dos pais permeia o palco de escolas com profissionais capacitados para atender às particularidades dos seus filhos. Já a questão cinco içava a problemática "de que forma você (pai/ mãe) acredita contribuir na inserção do (a) seu (sua) filho (a) na escola?", onde obteve-se por retorno:

\footnotetext{
Busca de informações sobre os direitos e deveres enquanto cidadão que deve ser legalmente incluído na educação/ escolas regulares. Exigir o cumprimento das legislações vigentes do TEA. Participação na vida escolar do filho com TEA. (E1)

Sempre que possível vou na escola para saber ele está acompanhando (SIC). Tenho ótimo diálogo com a professora de apoio. No início do ano levo, entrego para todos os professores os laudos, relatórios e observações de como lidar e respeitar os comportamentos dele. $(\boldsymbol{E} 3)$
}

Procurando as terapias necessárias, auxiliando e estimulando a criança nas tarefas e atividades propostas. (E6)

De tal maneira, vê-se pelas respostas uma correlação entre a necessidade de uma atuação mútua entre ambiente escolar e domiciliar, objetivando um atendimento de equidade a cada indivíduo. A exigência de que a legislação se faça, de apresentar os direitos desses cidadãos e em especial os deveres que devem ser cumpridos em prol desses atores são dedicações a nível Federal, uma vez que objetivam "II - a participação da comunidade na formulação de políticas públicas voltadas para as pessoas com transtorno do espectro autista e o controle social da sua implantação, acompanhamento e avaliação" (BRASIL, 2012, p. 2).

A sexta pergunta, assim, buscava perceber se havia preferência, por parte dos pais, em inserir seu filho (a) numa escola pública ou particular. Destes, $41 \%$ apontaram o interesse pela escola pública, justificando que falta "diretriz̨es de inclusão" (E1) e "aceitação de pais e professores" (E6). Indo em contramão, $41 \%$ assinalaram que optaram pela escola particular, ora que é "visto que existem inúmeras reclamações de pais em relação ao ensino aprendizado e na forma que o professor trabalha errado com o autista" (E7) e por "ficar receosa com a escola pública" (E11). Mais ainda, 18\% abalizaram que é indiferente a escola, haja vista que "nenhuma escola está preparada para receber o filho" (E4) ou "não tem profissionais capacitados para com eles trabalhar" (E5). 
A caminho de concluir este artigo, teve-se como pergunta final "se seu filho já está inserido em escola pública ou particular, avalie o trabalho pedagógico desenvolvido pela escola para com seu fillho". Obteve-se por retorno que $33 \%$ dos pesquisados consideram como bom; $17 \%$ com regular; $17 \%$ como excelente e 33\% não souberam informar. É notório entre os pais, suas preocupações e limitações acerca do que seus filhos poderão enfrentar ao se inserirem numa sala de aula, desde dificuldades de adaptação até o fato de talvez não receberem atendimento especializado através de um tutor capacitado.

Os índices baixos de 17\% em "regular" e "excelente" refletem uma precarização docente e acentuada, como Schmidt et al (2019), já havia alertado que, por resposta, demonstra a insegurança por parte dos pais de que seus filhos terão um ensino que, de fato, preserve a equidade. Pode-se, mais ainda, notar que as respostas detêm proximidades estabelecidas e reveladas pelas interações sociais que fazem (ora com professores e escola, ora entre os pais).

\section{Considerações finais}

Não pertence a esta pesquisa exibir conclusões, e sim, pretender criar novos debates e estudos, já que ao abordar um objeto como a Educação Inclusiva, com ênfase nas crianças diagnosticadas com Transtorno do Espectro Autista, detém variadas óticas de interpretação. Desde o resgate na história do que se têm, sua força nos campos sociais, acadêmicos; econômicos e políticos, bem como se sustenta num palco de inserção destes cidadãos nas escolas de ensino regular, este trabalho, todavia, teve ênfase em analisar e exibir as representações deste novo episódio na vida de crianças com TEA, a partir das declarações dos sujeitos.

Com o recebimento dos dados, é de relevância uma análise aprofundada e particularizada, seguida então de um estudo mais adjunto, que autentique -ou não- o que se conseguiu. Faz-se necessário estabelecer outras pesquisas que oportunizem avançar nos temas de Autismo, Atendimento e Educação Especial; Políticas Públicas de Inclusão; Comunicação Governamental sobre o TEA e como se conecta com os pesquisados deste trabalho. Reflexões essas que não tomaram aqui o escopo.

O estudo marcou para o caso de que as perspectivas dos pais de crianças diagnosticadas com autismo são dirigidas, fundamentalmente num palco simbólico, onde suas aparências patrocinam representações que os unem na premissa de que as escolas não se encontram capacitadas para atender seus filhos. Estas apropriações se estabelecem como resultado da sua experiência pessoal e do que imagina ser, essas declaradas após tratamento das respostas obtidas. 
Para finalizar, é importante salientar os limites da pesquisa aqui descrita e a impossibilidade de generalizações, indicando que há necessidade de investigar outros perfis de progenitores nessa temática, para efeito comparativo, pois sobre esse termo na atualidade há um espectro de empreendimentos diferentes. Aqui a análise ancorada procurou contemplar a interpretação de diferentes indivíduos sobre uma realidade que seus filhos e filhas partilharão, tal qual a circularidade da comunicação frequente entre estes explicando suas representações similares, haja vista serem construídas a partir de experiência pessoal e coletiva do grupo que vivencia e conversa sobre uma mesma realidade.

\section{Referências}

ARRUDA, A. Teoria das representações sociais e teorias de gênero. Cad. Pesqui., São Paulo, n. 117, p. 127-147, nov. 2002. Disponível em: http://www.scielo.br/scielo.php?script=sci_arttext\&pid=S0100-15742002000300007\&lng=en\&nrm=iso. Acesso em 17 set. 2019.

ASSOCIAÇÃO BRASILEIRA DE AUTISMO. ABA. História e Atuação [on-line]. Disponível em: http://www.autismo.org.br/site/abra/historia-e-atuacao.html. Acesso em 18 jul. 2019.

AZEVEDO. M. O. Práticas pedagógicas desenvolvidas com alunos com transtorno do espectro autista na escola regular: uma revisão integrativa da literatura. 2017. 153p. Dissertação (Mestrado em Educação) Universidade Federal do Rio Grande do Norte, Natal, 2017.

BRASIL. Ministério da Educação. Conselho Nacional de Educação. Conselho Pleno. Resolução CNE/CP n. 1, de 15 de maio de 2006. Institui Diretrizes Curriculares Nacionais para o Curso de Graduação em Pedagogia, licenciatura. Brasília, 2006. Disponível em: http://portal.mec.gov.br/cne/arquivos/pdf/rcp01_06.pdf. Acesso em 24 out. 2019.

BRASIL. Constituição (1988). Constituição da República Federativa do Brasil, Brasília, DF. Lei No 12.764 de 27 de dezembro de 2012. Institui a Politica Nacional de Proteção dos Direitos da Pessoa com Transtorno do Espectro Autista. Disponível em: https://www2.camara.leg.br/legin/fed/lei/2012/lei12764-27-dezembro-2012-774838-publicacaooriginal-138466-pl.html. Acesso em 10 nov. 2019.

CABRAL, T. L. O.; SILVA, J. E. O.; SAITO, C. E. Realidade do Intercâmbio e da Mobilidade Acadêmica na Universidade Federal de Santa Catarina. In: XI Colóquio Internacional sobre Gestão Universitária na América do Sule II Congresso Internacional IGLU, 2011.

GIL, A. C. Como elaborar projetos de pesquisa. São Paulo. Ed: Atlas, 2008.

JODELET, D. Representações sociais: um domínio em expansão. Rio de Janeiro: Ed: EdUERJ, 2001. p.17-42.

LOPES, T. J. S. As representações sociais e a educação. In XI Congresso Nacional de Educação EDUCERE, 2013. Disponível em: http://educere.bruc.com.br/ANAIS2013/pdf/90776744.pdf. Acesso em 04 out. 2019.

MANDAL, A. News Medical Life Science [on-line]. Disponível em: https://www.newsmedical.net/health/Autism-History-(Portuguese).aspx. Acesso em 10 nov. 2019. 
MOSCOVICI, S. Das representações coletivas às representações sociais: elementos para uma histórica. In JODELET, D. (Orgs.) Representações sociais: um domínio em expansão. Rio de Janeiro: Ed: EdUERJ, 2001. p. 45-66.

NASCIMENTO, F. F.; CRUZ, M. M.; BRAUN, P. Escolarização de pessoas com transtorno do espectro do autismo a partir da análise da produção científica. Arquivos Analíticos de Políticas Educativas, v. 25, n. 125, 2016.

NUNES, D. R. P.; SCHMIDT, C. Educação Especial e Autismo: Das Práticas Baseadas em Evidências à Escola. Cad. Pesqui., São Paulo, v. 49, n. 173, p. 84-103, set. 2019. Disponível em: http://www.scielo.br/scielo.php?script=sci_arttext\&pid=S0100-

$15742019000300084 \& \operatorname{lng}=$ en\&nrm $=$ iso

. Acesso em 17nov. 2019.

NUNES, D. R. P.; AZEVEDO, M. Q. O.; SCHMIDT, C. Inclusão educacional de pessoas com autismo no Brasil: uma revisão da literatura. Revista Educação Especial, Santa Maria, v. 26, n. 47, p. 557-572, set./dez. 2013.

OLIVEIRA, J.; PAULA, C. S. Estado da arte sobre inclusão escolar de alunos cm transtornos do espectro do autismo no Brasil. Cadernos de Pós-Graduação em Distúrbios do Desenvolvimento, São Paulo, v. 12 , n. 2, p. 53-65, 2012.

PEREIRA, E. C. Os processos formativos do professor de alunos com transtorno do espectro autista: contribuições da teoria histórico-cultural. 2016. Tese (Doutorado em Educação) - Universidade de São Paulo, São Paulo, 2016.

PESAVENTO, S. J. Em busca de uma outra história: imaginando o imaginário. Revista Brasileira de História. São Paulo, v. 15, n. 29, 1995. Disponível em: https://www.anpuh.org/arquivo/download?ID_ARQUIVO=3770. Acesso em 28 out. 2019.

SCHMIDT, C.; NUNES, D. R. P.; PEREIRA, D. M.; OLIVEIRA, V. F.; NUERNBERG, A. H.; KUBASKI, C. Inclusão escolar e autismo: uma análise da percepção docente e práticas pedagógicas. Revista Psicologia: Teoria e Prática, v. 17, n. 3, p. 222-235, jan./abr. 2016.

SACCO DOS ANJOS, F.; GODOY, W. I.; CALDAS, N. V. As feiras-livres de Pelotas sob o império da globalização: perspectivas e tendências. Pelotas/RS. Ed: Editora e Gráfica Universitária, 2005.

SÊGA, R. A. O conceito de representação social nas obras de Denise Jodelet e Serge Moscovici. Anos 90. Porto Alegre, n. 13, julho de 2000. Disponível em: https://doi.org/10.22456/1983-201X.6719. Acesso em 28 out. 2019.

SEVERINO, A. J. Metodologia do Trabalho Cientifico. 23ª ed., $5^{a}$ reimpressão. São Paulo. Ed: Cortez, 2007.

VERGARA, S. C. Projetos e relatórios de pesquisa em administração. São Paulo. Ed: Atlas, 2004.

WUO, A. S. Educação de pessoas com transtorno do espectro do autismo: estado do conhecimento em teses e dissertações nas regiões Sul e Sudeste do Brasil (2008-2016). Saude soc., São Paulo, v. 28, n. 3, p. 210-223, set. 2019. Disponível em:

http://www.scielo.br/scielo.php?script=sci_arttext\&pid=S010412902019000300210\&lng=en\&n rm=iso. Acesso em 28 out. 2019. 